\title{
Medically unexplained physical symptoms and work functioning over 2 years: their association and the influence of depressive and anxiety disorders and job characteristics
}

\author{
Madelon den Boeft ${ }^{1 *}$, Jos W. R. Twisk², Trynke Hoekstra², Berend Terluin ${ }^{1}$, Brenda W. J. H. Penninx ${ }^{3}$,
} Johannes C. van der Wouden ${ }^{1}$, Mattijs E. Numans ${ }^{4,1}$ and Henriette E. van der Horst ${ }^{1}$

\begin{abstract}
Background: Medically unexplained physical symptoms (MUPS) are highly prevalent and may affect work functioning. In this study we aimed to assess the longitudinal association between MUPS and work functioning over 2 years and the influence of job characteristics and depressive and anxiety disorders on this association.

Methods: We assessed the longitudinal association between MUPS and work functioning, operationalized in terms of absenteeism and disability at work, in 1887 working participants from the Netherlands Study of Depression and Anxiety (NESDA). The NESDA study population included participants with a current depressive and/or anxiety disorder, participants with a lifetime risk and/or subthreshold symptoms and healthy controls. Absenteeism was assessed with the Health and Labour Questionnaire Short Form and disability with the World Health Organization Disability Assessment Schedule II. MUPS were measured with the Four Dimensional Symptom Questionnaire. Measurements were taken at baseline and at 2 years follow-up. We used mixed model analyses to correct for the dependency of observations within participants.

Results: MUPS were positively associated with disability (regression coefficient $0.304 ; 95 \% \mathrm{Cl} 0.281-0.327$ ) and with short and long-term absenteeism over 2 years (OR 1.030, $95 \%$ Cl 1.016-1.045; OR 1.099, $95 \%$ Cl 1.085-1.114). After adjusting for depressive disorders, anxiety disorders and job characteristics, associations weakened but remained significant.
\end{abstract}

Conclusion: Our results show that MUPS were positively associated with disability and absenteeism over 2 years, even after adjusting for depressive and anxiety disorders and job characteristics. This suggests that early identification of MUPS and adequate management is important.

Keywords: Medically unexplained physical symptoms, Work functioning, Disability, Absenteeism, Psychiatric disorders

\footnotetext{
* Correspondence: m.denboeft@vumc.nl

'Department of General Practice \& Elderly Care Medicine, EMGO Institute for

Health and Care Research, VU University Medical Center, Amsterdam, The

Netherlands

Full list of author information is available at the end of the article
} 


\section{Background}

Medically unexplained physical symptoms (MUPS) are often presented to both primary and secondary health care physicians and may have major impact on daily functioning $[1,2]$. MUPS are physical symptoms not satisfactorily explained by a somatic underlying condition after an adequate medical examination and represent a broad spectrum of symptoms in varying degrees of severity [3, 4].

It is known that MUPS interfere with work functioning, both in terms of absenteeism and disability [5-7]. Not being able to work or not performing at work optimally is not only a burden for patients and their direct environment, but also for the community due to increasing costs $[8,9]$.

In the Netherlands, studies among workers have shown that high levels of somatic symptoms and distress are determinants for prolonged absenteeism and enduring disabilities $[6,10,11]$. It was also shown that the prevalence of severe MUPS was higher in the long-term absent employees compared to the non-sick working population [7]. These findings are supported by international studies $[12,13]$ and the relevance of the problem is reinforced by a 10-year follow-up study by Rask et al., who concluded that not only severe MUPS have significant impact on work functioning, but also mild and recent onset MUPS [5]. Despite the relevance of absenteeism and disability from work caused by MUPS, limited research has been performed to assess potential influencing factors on the relationship between MUPS and work functioning and their association over time [14].

It is known that unfavourable job characteristics, such as long working hours and low occupational status, can influence someone's functioning negatively. Lower graded jobs are associated with more absenteeism and disability, compared to higher graded jobs [15]. The same applies to high demands, whether or not in combination with low support by colleagues, low task control [16-18] and long working hours [19]. The question arises to what extent this also applies to MUPS. Furthermore, as we know that MUPS are often accompanied by depressive and anxiety disorders, it is important to understand the influence of comorbidity of depressive and/or anxiety disorders on work functioning over time in patients considered having MUPS [20].

Deeper insight into the association between MUPS and work functioning and influencing factors such as job characteristics and comorbid psychiatric disorders can assist physicians in the early identification of patients at risk and it may provide opportunities to develop adequate management and prevention strategies. Therefore, in this longitudinal study we first assessed the association between MUPS and work functioning, both absenteeism and disability at work, over 2 years. Second, we investigated the influence of job characteristics and depressive and/or anxiety disorders as potential confounders in this association.

\section{Methods \\ Design and study population}

The present longitudinal analysis is part of the Netherlands Study of Depression and Anxiety (NESDA). The NESDA is a multisite naturalistic cohort study, which aims to describe the long-term course and consequences of depressive and anxiety disorders and to examine its predictors. A detailed description of the design and sampling is provided elsewhere [21]. In summary, 2981 participants between 18 and 65 years were included. The NESDA study population consisted of participants with current depressive and/or anxiety disorders, participants with a lifetime risk or subthreshold symptoms and healthy controls. Recruitment of participants took place in primary care practices $(n=1610)$, outpatient mental health care institutions $(n=807)$ and in the general population $(n=564)$. Exclusion criteria were not being fluent in the Dutch language or having a primary diagnosis of a psychotic, obsessive, bipolar or severe substance abuse disorder. Baseline data (T0) were collected between 2004 and 2007. The research protocol was approved by the ethical committees of participating universities and performed in accordance with the ethical standards of the Declaration of Helsinki. All participants provided written informed consent.

For the present study, we selected working participants $(n=1887)$, i.e. participants who had a paid job for more than $8 \mathrm{~h}$ a week at baseline (T0). Of them, 1665 (88.2 \%) completed the questionnaires regarding work functioning and MUPS and were therefore included in this study (591 male, 1074 female). After 2 years (T1), 1455 (87.4\%) participants had a follow up assessment.

\section{Work functioning}

We conceptualized work functioning in terms of disability at work and absenteeism from work.

Disability at work was assessed with the validated World Health Organization Disability Assessment Schedule II (WODAS-II) [22]. This is a 36-item instrument, assessing functioning and disability and focusing on six subscales regarding several domains in life. We focused on the domain of work activities which includes four items: 1) difficulty in day-to-day work, 2) difficulty in doing most important work tasks well, 3) difficulty in getting all work done and 4) difficulty in getting work done as quickly as needed. Respondents rated difficulty on a 5-point scale, ranging from 1 (none) to 5 (extreme, cannot do). Therefore the summated work domain scale has a range from 4 to 20 with higher scores representing a higher level of disability. 
Absenteeism from work was assessed with the validated Health and Labour Questionnaire Short Form [23] and was computed by dividing the number of absent days from work during the past 6 months because of health problems by the number of actual work days per week. As this variable does not meet normality assumptions, we categorized it into three categories: no absenteeism, shortterm absenteeism ( $<2$ weeks) and long-term absenteeism ( 2 weeks or longer), cf. Plaisier et al. [24]. The latter two categories made a distinction possible between short-term absenteeism, probably due to self-limiting conditions such as common colds, and long-term absenteeism, which could indicate more chronic conditions.

\section{Medically unexplained physical symptoms}

MUPS were measured with the somatization scale of the validated Four Dimensional Symptoms Questionnaire (4DSQ), a self-report questionnaire developed to measure distress, depression, anxiety and somatization as separate dimensions in primary care (25). The somatization scale comprises 16 items, all physical symptoms. The response categories on a 5-point Likert scale are worded as follows: "no", "sometimes", "regularly", "often" and "very often or constantly". In order to arrive at scale scores, the responses are scored as 0 for "no", 1 for "sometimes" and 2 for "regularly", "often" and "very often or constantly" and the item scores were summated into a scale score, as done by Terluin et al. with a range of 0-32 [25], indicating that MUPS is considered to be a summation of physical symptoms. Additionally, in order to facilitate clinical use and to overcome the fact that there is no linear relationship between MUPS and work functioning, we repeated the analyses with a dichotomized scale using 11 points as a clinical cut-off score, since a score of 11 or higher is considered to indicate MUPS [25].

\section{Job characteristics}

Job characteristics were conceptualized as working hours, occupational status and psychosocial working conditions. The occupational status variable was created using the occupational categories provided by Statistics Netherlands and additional self-reported information on employment status. The original eleven categories of Statistics Netherlands were recoded into five categories: 1) high graded non-manual workers, 2) medium or low skilled non-manual workers, 3) self-employed, 4) high skilled manual workers and 5) medium or low skilled manual workers, as was done by Plaisier et al. [26]. Psychosocial working conditions consist of job demands, job control and job support and were measured with a questionnaire consisting of dichotomous items, based on the demands/control model [27]. Data on job characteristics were only gathered at baseline (T0). Unfortunately for $30 \%$ of the participants no information regarding job characteristics could be obtained.

\section{Depressive and/or anxiety disorders}

The presence of depressive disorders, including major depressive disorder and dysthymia as well as anxiety disorders, including generalized anxiety disorder, panic disorder with or without agoraphobia, social phobia and/or agoraphobia without panic disorder, were diagnosed with the validated Composite Interview Diagnostic Instrument (CIDI version 2.1). We only took into account diagnoses established during the past 6 months. Trained research staff interviewed all participants.

\section{Socio-demographic covariates and chronic diseases}

Based on previous research on the association between MUPS and work functioning, the following covariates were considered as possible confounders: gender, age, level of education, marital status and the number of chronic diseases $[5,28]$. We divided the level of education into three groups (basic, intermediate, high), derived from the standard classification of education from Statistics Netherlands [29]. Marital status was divided into two categories: participants married or living with a partner and participants not married or living without a partner. Participants were asked if they suffered from chronic diseases from each of the following categories: respiratory, cardiometabolic, musculoskeletal, digestive, neurological, endocrine and cancer. Diseases were only included if participants were currently treated with medicines or under specialist care. The number of diseases were summated into a scale score. Data on the covariates were only gathered at baseline (T0).

\section{Analysis}

Descriptive statistics are presented as mean with standard deviation for normally distributed continuous data, median and inter-quartile range for skewed continuous variables and as numbers and percentages for dichotomous and categorical variables.

To assess the association between MUPS and work functioning over 2 years (T0, T1), we used linear mixed model analyses for disability and multinomial logistic mixed model analyses for absenteeism. After crude analyses, we performed adjusted analyses where covariates (sociodemographic variables and the number of chronic diseases) were included in the model. Next, we examined the confounding role of depressive and/or anxiety disorders and job characteristics on the adjusted association between MUPS and work functioning, first separately and then combined.

Effects were expressed as regression coefficients (for disability) and odds ratios (ORs) (for absenteeism) with $95 \%$ confidence intervals $(\mathrm{CI})$, representing the longitudinal 
association between MUPS and work functioning on average over time, reflecting both the within and between subject relationship [30]. For absenteeism, 'no absenteeism' was used as the reference category.

As depressive and anxiety disorders were overrepresented in the NESDA cohort, we added interaction terms to the analysis to assess if depressive and/or anxiety disorders modify the association between MUPS and work functioning. We used all observations in our analyses. As we used a longitudinal design, missing data did not have to be imputed [30].

The statistical analyses were performed in MLwiN (version 2.31) and Stata (version 13).

\section{Results}

Table 1 shows the demographic and clinical characteristics of the study sample. At baseline, the mean age was 40 years and $65 \%$ were women. The median score for MUPS was 8 at baseline and 6 at 2 years follow up $(p<0.001)$. When using the clinical cut-off point of $37 \%$ had MUPS at T0 and $22 \%$ had MUPS at T1.

\section{The longitudinal association between MUPS and disability at work}

We found a strong positive association between MUPS and disability at work on average over time (Table 2). The estimated crude regression coefficient of 0.295 for MUPS, measured with the continuous 4DSQ somatization scale, in relation to disability at work can be interpreted as follows: for every unit increase/difference in the 4DSQ, there is a 0.295 increase/difference in the severity of disability. Depressive disorders had the greatest influence on the association between MUPS and disability as the regression coefficient became smaller, followed by anxiety disorders. However, the association between MUPS and disability remained statistically significant. Job characteristics did not affect the association. For the dichotomous 4DSQ comparable results were found.

When we examined whether the association between MUPS and disability was modified by depressive and/or anxiety disorders, we found a strong significant negative interaction for depressive disorders $(p<0.001)$ and a borderline significant negative interaction for anxiety disorders $(p=0.054)$, indicating that the association between MUPS and disability was weaker for participants with a depressive and/or anxiety disorder. For the dichotomous 4DSQ comparable results were found.

\section{The longitudinal association between MUPS and absenteeism from work}

We found a strong positive association between MUPS and short-term absenteeism and an even stronger effect for long-term absenteeism, on average over time, both
Table 1 Demographic and clinical characteristics of research population

\begin{tabular}{|c|c|c|}
\hline & Baseline (T0) & $\begin{array}{l}\text { Two year follow } \\
\text { up (T1) }\end{array}$ \\
\hline & $(n=1665)$ & $(n=1455)$ \\
\hline \multicolumn{3}{|l|}{ Socio-demographics } \\
\hline Females, number (\%) & $1074(64.5)$ & $941(64.7)$ \\
\hline Age in years, mean (SD) & $40.8(11.7)$ & $40.1(11.4)$ \\
\hline \multicolumn{3}{|c|}{ Level of education, number (\%) } \\
\hline Basic & $68(4.1)$ & $56(3.8)$ \\
\hline Intermediate & $886(53.2)$ & $749(51.5)$ \\
\hline High & $711(42.7)$ & $650(44.7)$ \\
\hline $\begin{array}{l}\text { Number of chronic } \\
\text { diseases, median (IQR) }\end{array}$ & $0.00(0.00-1.00)$ & $0.00(0.00-1.00)$ \\
\hline $\begin{array}{l}\text { Married or with partner, } \\
\text { number (\%) }\end{array}$ & $1223(73.5)$ & $1047(72.0)$ \\
\hline \multicolumn{3}{|c|}{ Medically unexplained physical symptoms } \\
\hline $\begin{array}{l}\text { Total score (0-32), } \\
\text { median (IQR) }\end{array}$ & $8.00(4.00-13.00)$ & $6.00(3.00-10.00)$ \\
\hline $\begin{array}{l}\text { Somatisation (cut-off } \\
11 \text { points) (\%) }\end{array}$ & $621(37.3)$ & $322(22.1)$ \\
\hline \multicolumn{3}{|l|}{ Work functioning } \\
\hline \multicolumn{3}{|l|}{ Absenteeism, number (\%) } \\
\hline No absenteeism & $786(47.2)$ & $804(55.3)$ \\
\hline $\begin{array}{l}\text { Short term absenteeism } \\
(<2 \text { weeks })\end{array}$ & $508(30.5)$ & $467(32.1)$ \\
\hline $\begin{array}{l}\text { Long term absenteeism } \\
\text { ( } \geq 2 \text { weeks) }\end{array}$ & $371(22.3)$ & $184(12.6)$ \\
\hline $\begin{array}{l}\text { Disability (0-20), } \\
\text { mean (SD) }\end{array}$ & $8.5(4.5)$ & $7.1(3.7)$ \\
\hline \multicolumn{3}{|c|}{ Job characteristics, median (IQR) } \\
\hline Working hours & $32.00(24.00-38.00)$ & - \\
\hline Job demands & $0.40(0.20-0.80)$ & - \\
\hline Job control & $0.79(0.61-0.93)$ & - \\
\hline Job support & $0.75(0.50-1.00)$ & - \\
\hline \multicolumn{3}{|c|}{ Psychiatric comorbidity (number, \%) } \\
\hline Depressive disorder & $572(34.4)$ & 285 (19.6) \\
\hline Anxiety disorder & $653(39.2)$ & $333(22.9)$ \\
\hline
\end{tabular}

Means with standard deviations are given for normally distributed continuous variables, medians and inter-quartile ranges for skewed continuous variables and frequencies with percentages for dichotomous and categorical variables. $S D$ standard deviation. IQR interquartile range

compared to the reference category 'no absenteeism' (Table 3). Depressive disorders had the strongest influence on the association between MUPS (with use of the continuous 4DSQ) and short-term absenteeism (37 \% decrease in regression coefficient), followed by job characteristics (mainly caused by job support and job control; 33 and $37 \%$ decrease in regression coefficient) and anxiety disorders (20\% decrease in regression coefficient). Depressive disorders also had the strongest 
Table 2 Analyses results on the association between MUPS and disability at work over 2 years

\begin{tabular}{|c|c|c|}
\hline & $\begin{array}{l}\text { Regression coefficient } \\
\text { (95\% Cl) } \\
\text { (with continuous 4DSQ) }\end{array}$ & $\begin{array}{l}\text { Regression coefficient } \\
(95 \% \mathrm{Cl} \text { ) } \\
\text { (with dichotomous 4DSQ) }\end{array}$ \\
\hline Crude & $0.30(0.27-0.32)$ & $3.23(2.93-3.53)$ \\
\hline Adjusted $^{a}$ & $0.30(0.28-0.33)$ & $3.21(2.91-3.52)$ \\
\hline \multicolumn{3}{|l|}{ Univariable $^{b}$} \\
\hline Anxiety disorder & $0.26(0.24-0.29)$ & $2.68(2.37-3.00)$ \\
\hline $\begin{array}{l}\text { Depressive } \\
\text { disorder }\end{array}$ & $0.23(0.21-0.26)$ & $2.39(2.10-2.70)$ \\
\hline \multicolumn{3}{|l|}{ Job characteristics } \\
\hline Working hours & $0.30(0.28-0.33)$ & $3.21(2.90-3.52)$ \\
\hline $\begin{array}{l}\text { Occupational } \\
\text { status }\end{array}$ & $0.32(0.29-0.34)$ & $3.20(2.83-3.57)$ \\
\hline Job demands & $0.30(0.28-0.33)$ & $3.05(2.71-3.38)$ \\
\hline Job control & $0.30(0.28-0.33)$ & $3.00(2.67-3.34)$ \\
\hline Job support & $0.30(0.27-0.32)$ & $2.91(2.58-3.25)$ \\
\hline Multivariable ${ }^{b}$ & $0.21(0.18-0.24)$ & $1.95(1.59-2.31)$ \\
\hline
\end{tabular}

$4 D S Q$ four-dimensional symptom questionnaire

${ }^{a}$ Adjusted for age, gender, level of education, marital status, number of chronic diseases

bUnivariable: influence of covariates separately; Multivariable: influence of covariates combined

influence on the association between MUPS and longterm absenteeism ( $40 \%$ decrease in regression coefficient), followed by anxiety disorders (20\% decrease in regression coefficient). Job characteristics did not affect the association. Despite adjusting for these confounders, the association between MUPS and absenteeism remained significant. For the dichotomous 4DSQ comparable results were found.
When we examined whether the association between MUPS and absenteeism was modified by depressive and/or anxiety disorders, we only found a negative interaction for anxiety disorders and long-term absenteeism $(p=0.022)$, indicating that the association between MUPS and longterm absenteeism was weaker for participants with an anxiety disorder. We found no significant interaction for depressive disorders. For the dichotomous 4DSQ comparable results were found.

\section{Discussion \\ Summary of results}

With this study we aimed to assess the association between MUPS and work functioning over 2 years and the influence of job characteristics and depressive and anxiety disorders on this association. We showed that MUPS was positively associated with disability and absenteeism from work over 2 years, with a stronger effect for long-term absenteeism than for short-term absenteeism. Depressive and anxiety disorders weakened the association between MUPS and work functioning, but the association remained significant. Job characteristics only weakened the association between MUPS and shortterm absenteeism, but again the association remained significant.

\section{Comparison with existing literature}

Little research has been performed on MUPS and work functioning. Even though our study is not directly comparable with previously conducted research because of use of different designs and populations among other things, our study results are in line with other studies.

Table 3 Analyses results on the association between MUPS and absenteeism from work over 2 years

\begin{tabular}{|c|c|c|c|c|}
\hline & \multicolumn{2}{|c|}{ Odds ratio (95\% Cl) (with continuous 4DSQ) } & \multicolumn{2}{|c|}{ Odds ratio (95 \% Cl) (with dichotomous 4DSQ) } \\
\hline & Short-term absenteeism & Long-term absenteeism & Short-term absenteeism & Long-term absenteeism \\
\hline Crude & $1.03(1.02-1.05)$ & $1.11(1.09-1.13)$ & $1.41(1.19-1.67)$ & $3.64(3.06-4.34)$ \\
\hline Adjusteda $^{\mathrm{a}}$ & $1.03(1.02-1.05)$ & $1.10(1.09-1.11)$ & $1.37(1.15-1.62)$ & $3.15(2.62-3.78)$ \\
\hline \multicolumn{5}{|l|}{ Univariable $^{b}$} \\
\hline Anxiety disorder & $1.02(1.01-1.04)$ & $1.08(1.06-1.09)$ & $1.26(1.05-1.50)$ & $2.47(2.04-2.99)$ \\
\hline Depressive disorder & $1.02(1.01-1.03)$ & $1.06(1.04-1.07)$ & $1.21(1.02-1.45)$ & $2.08(1.72-2.52)$ \\
\hline \multicolumn{5}{|l|}{ Job characteristics } \\
\hline Working hours & $1.03(1.02-1.05)$ & $1.10(1.08-1.11)$ & $1.37(1.15-1.63)$ & $3.15(2.62-3.78)$ \\
\hline Occupational status & $1.03(1.01-1.04)$ & $1.10(1.08-1.12)$ & $1.27(1.03-1.57)$ & $2.81(2.26-3.50)$ \\
\hline Job demands & $1.02(1.01-1.04)$ & $1.09(1.08-1.11)$ & $1.29(1.07-1.56)$ & $2.79(2.28-3.41)$ \\
\hline Job control & $1.02(1.01-1.03)$ & $1.09(1.07-1.11)$ & $1.22(1.01-1.48)$ & $2.66(2.17-3.25)$ \\
\hline Job support & $1.02(1.01-1.04)$ & $1.09(1.07-1.11)$ & $1.22(1.01-1.48)$ & $2.69(2.20-3.30)$ \\
\hline Multivariable ${ }^{c}$ & $1.01(1.00-1.03)$ & $1.04(1.02-1.06)$ & $1.03(0.82-1.30)$ & $1.61(1.26-2.05)$ \\
\hline
\end{tabular}

Reference category: 'no absenteeism'. 4DSQ four-dimensional symptom questionnaire

${ }^{a}$ Adjusted for age, gender, level of education, marital status, number of chronic diseases

bUnivariable: influence of covariates separately

cMultivariable: influence of covariates combined 
In a prospective study, Roelen et al. showed that various MUPS were associated with absenteeism and concluded that the more symptoms at baseline, the higher the risk of absenteeism a year later [10]. In two crosssectional studies, Hoedeman et al. concluded that $15 \%$ of employees on sickness leave suffered from severe MUPS and that severe MUPS was associated with four to six times more comorbid depressive and anxiety disorders. The authors used a cut-off score of 15 on the PHQ-15 for the categorisation of severe MUPS.

Furthermore, they concluded that employees with severe MUPS had a longer duration of absenteeism [6, 7]. In a 5-year follow-up study, Loengaard et al. found that MUPS patients had an increased risk of long-term absenteeism compared to healthy participants [31]. Rask et al. performed a 10-year follow-up study and found that recent onset MUPS and somatoform disorders have significant negative long-term impact on patient work functioning [5]. They also concluded that although depressive and anxiety disorders influence the association between MUPS and work functioning, both psychiatric disorders did not fully explain the effect, which corresponds with our findings.

We are not aware of earlier studies that examined the influence of specific job characteristics in patients with MUPS. However, there are some studies that describe the association of job characteristics with work functioning and mental health problems in the general working population. We found that job support and job control weakened the association between MUPS and shortterm absenteeism, which is in line with North et al. and Melchior et al. [16, 18]. Christensen et al. found that absenteeism rates were higher for lower graded jobs compared to higher graded jobs, while Sparks et al. found that the number of working hours might be important for work functioning [19]. We did not find the same results for MUPS.

\section{Strengths and limitations}

We believe our study has several methodological strengths, in particular the large sample of participants, recruited from primary care and secondary mental health care, and the longitudinal design. Also, all analyses were adjusted for the number of chronic diseases. Finally, for the assessment of depressive and anxiety disorders, structured interviews were used.

Our findings should be interpreted in the light of several limitations. First, as for all questionnaires assessing MUPS, the 4DSQ lacks clinical judgement. However, the 4DSQ highly correlates with the Patient Health Questionnaire-15 and the Symptom Checklist-90, other questionnaires widely used to measure MUPS. In our study we defined MUPS based on the score of the 4DSQ and MUPS is defined as a summation of physical symptoms which often remain unexplained after appropriate examination. It should be kept in mind that the definition of MUPS is controversial, i.e. whether it represents a specific disorder or whether it is a way of presenting different types of emotional distress. Second, time windows differed between the concepts: disability was measured over the past month and absenteeism over the past 6 months, while MUPS was measured over the past week. However, we do not believe that the results were much affected by this incongruence. In an additional analysis we found a correlation coefficient of 0.72 between MUPS at T0 and T1, indicating a quite stable pattern of MUPS over 2 years. Also the additional time lag analysis, relating MUPS at T0 to disability and absenteeism at $\mathrm{T} 1$, revealed more or less the same results (data not shown). Third, because job characteristics had $30 \%$ missing values, we repeated the crude analyses in a reduced dataset with only complete cases. The results showed that job characteristics still had a weakening influence on the association MUPS and short-term absenteeism, but that this influence was weaker. Fourth, we have no information on the actual reasons for disability and absenteeism. Fifth, participants with depressive and/or anxiety disorders were oversampled in our study population. It is often assumed that the observed strong association between MUPS and work functioning is because of this oversampling. With the interaction analyses however, we showed that it is actually the other way around: that within participants without these disorders the association between MUPS and work functioning was stronger than in participants with these disorders. Therefore we wanted to emphasize that the observed associations may also hold for the general population. It should be noted that the negative interaction between MUPS and depressive/ anxiety disorders is probably due to the strong association between depressive/anxiety disorders and disability.

Finally, the population at follow-up is slightly healthier than the original population. Although it is possible that those who did not complete follow-up measurements were more severely disturbed, we do not think that this highly influences the results of our study. However, if there is an influence, the magnitude of the observed association between MUPS and work functioning might be an underestimation of the real association due to this phenomena.

\section{Implication for clinical practice and future research}

Disability and absenteeism may lead to a decreased quality of life for patients and high direct and indirect costs $[8,9,32]$. As we found that MUPS have an independent negative association with work functioning, attention should be paid to preventive measures in the work place, early identification of MUPS and adequate treatment. However, as depressive and anxiety disorders weakened the association between MUPS and work 
functioning, physicians should be aware of signs and symptoms of depressive or anxiety disorders.

As said, little is known about work environment and only a small number of studies assessed phenomena associated with disability and absenteeism among workers with MUPS [14]. With our analyses, we have shown that job support and job control influence the association between MUPS and mainly short-term absenteeism. More insight is needed about favourable job characteristics to develop interventions for prevention and treatment and return to work programs.

\section{Conclusions}

Our results show that MUPS were positively associated with disability and absenteeism over 2 years, even after adjusting for depressive and anxiety disorders and job characteristics. This suggests that early identification of MUPS and adequate management is important.

\section{Ethics approval and consent to participate}

The research protocol was approved by the ethical committees of participating universities (Amsterdam, Leiden and Groningen) and performed in accordance with the ethical standards of the Declaration of Helsinki. All participants provided written informed consent.

\section{Consent for publication \\ Not applicable.}

\section{Availability of data}

Data can be made available on request.

\begin{abstract}
Abbreviations
4DSQ: four dimensional symptoms questionnaire; Cl: confidence interval; CIDI: composite interview diagnostic instrument; MUPS: medically unexplained physical symptoms; NESDA: Netherlands study of depression and anxiety; OR: odds ratio; WHO-DAS: world health organization disability assessment schedule.
\end{abstract}

\section{Competing interests}

The authors declare that they have no competing interests.

\section{Authors' contributions}

"All authors contributed to this project, in which MB was responsible for planning the project. BP obtained funding and supervised NESDA's data collection, MB analysed and interpreted the data with support from JT and JW. MB also drafted the manuscript. JT, BT, BP, MN, JW and HH were all involved in the design of the study and methodology. All authors supported $\mathrm{MB}$ in drafting and revising the manuscript. They all read this manuscript and gave their final approval for submission this version."

\section{Acknowledgements}

The authors would like to thank all contributors at the NESDA. The infrastructure of the NESDA is funded through the Geestkracht program of the Netherlands Organisation for Health Research and Development (ZonMw, grant number 10-000-1002) and is funded by participating universities and mental health care organizations (VU University Medical Center, GGZ inGeest, Arkin, Leiden University Medical Center, GGZ Rivierduinen, University Medical Center Groningen, Lentis, GGZ Friesland, GGZ Drenthe, Scientific Institute for Quality of Healthcare (IQ healthcare), Netherlands Institute for Health Services Research (NIVEL) and Netherlands Institute of Mental Health and Addiction (Trimbos).

\section{Funding}

This study was funded by a grant from VGZ Health Insurances and is part of the program for Innovation and Quality of Academic Primary Care. The funding source had no further involvement in this study.

\section{Author details}

'Department of General Practice \& Elderly Care Medicine, EMGO Institute for Health and Care Research, VU University Medical Center, Amsterdam, The Netherlands. ${ }^{2}$ Department of Epidemiology \& Biostatistics, EMGO Institute for Health and Care Research, VU University Medical Center, Amsterdam, The Netherlands. ${ }^{3}$ Department of Psychiatry, EMGO Institute for Health and Care Research, VU University Medical Center, Amsterdam, The Netherlands. ${ }^{4}$ Department of Public Health and Primary Care, Leiden University Medical Center, Leiden, The Netherlands.

Received: 8 December 2015 Accepted: 7 April 2016

Published online: 14 April 2016

\section{References}

1. Burton C. Beyond somatisation: a review of the understanding and treatment of medically unexplained physical symptoms (MUPS). Br J Gen Pract. 2003:53:231-9.

2. Kroenke K, Spitzer RL, Williams JBW. The PHQ-15: validity of a New measure for evaluating the severity of somatic symptoms. Psychosom Med. 2002;64:258-66.

3. Fink $\mathrm{P}$, Rosendal $\mathrm{M}$, Olesen F. Classification of somatization and functional somatic symptoms in primary care. Aust N Z J Psychiatry. 2005;39:772-81.

4. Smith RC, Dwamena FC. Classification and diagnosis of patients with medically unexplained symptoms. J Gen Intern Med. 2007;22:685-91.

5. Rask MT, Rosendal M, Fenger-Grøn M, Bro F, Ornbol E, Fink P. Sick leave and work disability in primary care patients with recent-onset multiple medically unexplained symptoms and persistent somatoform disorders: a 10-year follow-up of the FIP study. Gen Hosp Psychiatry. 2015;37:53-9.

6. Hoedeman R, Blankenstein AH, Krol B, Koopmans PC, Groothoff JW. The contribution of high levels of somatic symptom severity to sickness absence duration, disability and discharge. J Occup Rehabil. 2010;20:264-73.

7. Hoedeman R, Krol B, Blankenstein N, Krol B, Koopmans PC, Groothoff JW. Severe MUPS in a sick-listed population: a cross-sectional study on prevalence, recognition, psychiatric co-morbidity and impairment. BMC Public Health. 2009;9:440.

8. Konnopka A, Kaufmann C, König H-H, Heider D, Wild B, Szecseyni J, et al. Association of costs with somatic symptom severity in patients with medically unexplained symptoms. J Psychosom Res. 2013;75:370-5.

9. Konnopka A, Schaefert R, Heinrich S, Kaufmann C, Luppa M, Herzog W, et al. Economics of medically unexplained symptoms: a systematic review of the literature. Psychother Psychosom. 2012:81:265-75.

10. Roelen CAM, van der Pol TR, Koopmans PC, Groothoff JW. Identifying workers at risk of sickness absence by questionnaire. Occup Med Oxf Engl. 2006;56:442-6.

11. Terluin B, van Rhenen W, Anema JR, Taris TW. Psychological symptoms and subsequent sickness absence. Int Arch Occup Environ Health. 2011;84:825-37.

12. Norrmén G, Svärdsudd K, Andersson DKG. How primary health care physicians make sick listing decisions: the impact of medical factors and functioning. BMC Fam Pract. 2008;9:3.

13. Hansen A, Edlund C, Bränholm I-B. Significant resources needed for return to work after sick leave. Work Read Mass. 2005;25:231-40.

14. Aamland A, Malterud K, Werner EL. Phenomena associated with sick leave among primary care patients with medically unexplained physical symptoms: a systematic review. Scand J Prim Health Care. 2012;30:147-55.

15. Christensen KB, Labriola M, Lund T, Kivimäki M. Explaining the social gradient in long-term sickness absence: a prospective study of Danish employees. J Epidemiol Community Health. 2008;62:181-3.

16. North FM, Syme SL, Feeney A, Shipley M, Marmot M. Psychosocial work environment and sickness absence among British civil servants: the Whitehall II study. Am J Public Health. 1996;86:332-40.

17. Roelen CAM, Schreuder KJ, Koopmans PC, Groothoff JW. Perceived job demands relate to self-reported health complaints. Occup Med Oxf Engl. 2008;58:58-63.

18. Melchior M, Niedhammer I, Berkman LF, Goldberg M. Do psychosocial work factors and social relations exert independent effects on sickness absence? 
A six year prospective study of the GAZEL cohort. J Epidemiol Community Health. 2003;57:285-93.

19. Sparks K, Cooper C, Fried Y, Shirom A. The effects of hours of work on health: a meta-analytic review. J Occup Organ Psychol. 1997;70:391-408.

20. van Boven $K$, Lucassen $P$, van Ravesteijn $H$, Olde Hartman T, Bor H,

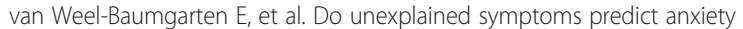
or depression? Ten-year data from a practice-based research network. Br J Gen Pract J R Coll Gen Pract. 2011;61:316-25.

21. Penninx BWJH, Beekman ATF, Smit JH, Zitman FG, Nolen WA, Spinhoven P, et al. The Netherlands study of depression and anxiety (NESDA): rationale, objectives and methods. Int J Methods Psychiatr Res. 2008;17:121-40.

22. Chwastiak LA, Von Korff M. Disability in depression and back pain: evaluation of the World Health Organization Disability Assessment Schedule (WHO DAS II) in a primary care setting. J Clin Epidemiol. 2003;56:507-514.

23. Bouwmans C, Jong KD, Timman R, Zijlstra-Vlasveld M, van der Feltz-Cornelis $C$, Tan SS, et al. Feasibility, reliability and validity of a questionnaire on healthcare consumption and productivity loss in patients with a psychiatric disorder (TiC-P). BMC Health Serv Res. 2013;13:217.

24. Plaisier I, Beekman ATF, de Graaf R, Smit JH, van Dyck R, Penninx BWJH. Work functioning in persons with depressive and anxiety disorders: the role of specific psychopathological characteristics. J Affect Disord. 2010:125:198-206.

25. Terluin B, van Marwijk HW, Adèr HJ, de Vet HCW, Penninx BWJH, Hermens MLM, et al. The four-dimensional symptom questionnaire (4DSQ): a validation study of a multidimensional self-report questionnaire to assess distress, depression, anxiety and somatization. BMC Psychiatry. 2006;6:34.

26. Plaisier I, de Graaf R, de Bruijn J, Smit J, van Dyck R, Beekman A, et al. Depressive and anxiety disorders on-the-job: the importance of job characteristics for good work functioning in persons with depressive and anxiety disorders. Psychiatry Res. 2012;200:382-8.

27. Karasek R, Theorell T. Healthy work, stress, productivity, and the reconstruction of working life. New York: Basic Books; 1990.

28. Aamland A, Malterud K, Werner EL. Patients with persistent medically unexplained physical symptoms: a descriptive study from Norwegian general practice. BMC Fam Pract. 2014;15:107.

29. Centraal Bureau voor de Statistiek. Available from www.cbs.nl. Accessed 27 Oct 2015

30. Twisk JWR. Applied longitudinal data analysis for epidemiology. 2nd ed. Cambridge: Cambridge University Press; 2013.

31. Loengaard K, Bjorner JB, Fink PK, Burr H, Rugulies R. Medically unexplained symptoms and the risk of loss of labor market participation - a prospective study in the Danish population. BMC Public Health. 2015;15:844.

32. Aamland A, Werner EL, Malterud K. Sickness absence, marginality, and medically unexplained physical symptoms: a focus-group study of patients' experiences. Scand J Prim Health Care. 2013;31:95-100.

\section{Submit your next manuscript to BioMed Central and we will help you at every step:}

- We accept pre-submission inquiries

- Our selector tool helps you to find the most relevant journal

- We provide round the clock customer support

- Convenient online submission

- Thorough peer review

- Inclusion in PubMed and all major indexing services

- Maximum visibility for your research

Submit your manuscript at www.biomedcentral.com/submit

C Biomed Central 